\title{
Transformations of Carbides During Tempering of D3 Tool Steel
}

Tadeusz Nykiel and Tadeusz Hryniewicz

\author{
(Submitted October 23, 2013; in revised form January 27, 2014; published online April 12, 2014)
}

\begin{abstract}
The studies were performed on $\mathrm{D} 3$ tool steel hardened after austenitizing at $1050{ }^{\circ} \mathrm{C}$ during 30 min and tempering at $200-700{ }^{\circ} \mathrm{C}$. Based on the diffraction studies performed from the extraction replicas, using electron microscopy, it was found that after 120-min tempering in the consecutive temperatures, the following types of carbides occur:
\end{abstract}

$$
\begin{aligned}
& 200{ }^{\circ} \mathrm{C} \rightarrow \varepsilon+\chi+\mathrm{Fe}_{3} \mathrm{C}, \quad 350{ }^{\circ} \mathrm{C} \rightarrow \varepsilon+\chi+\mathrm{Fe}_{3} \mathrm{C}, \\
& 500{ }^{\circ} \mathrm{C} \rightarrow \chi+\mathrm{M}_{3} \mathrm{C}+\mathrm{M}_{7} \mathrm{C}_{3}, \quad 600{ }^{\circ} \mathrm{C} \rightarrow \chi+\mathrm{M}_{3} \mathrm{C}+\mathrm{M}_{7} \mathrm{C}_{3}, \\
& 700{ }^{\circ} \mathrm{C} \rightarrow \mathrm{M}_{3} \mathrm{C}+\mathrm{M}_{7} \mathrm{C}_{3} .
\end{aligned}
$$

Apart from higher mentioned carbides, there are also big primary carbides and fine secondary $M_{7} C_{3}$ carbides occurring, which did not dissolve during austenitizing.

Keywords carbides, D3 tool steel, structure, tempering

\section{Introduction}

Basic studies concerned with the carbide precipitation during tempering of steel containing about $2 \% \mathrm{C}$ and $12 \% \mathrm{Cr}$ were performed by Sato et al. (Ref 1), Apajew (Ref 2), Kimura (Ref 3), and Głowacki (Ref 4). Sato et al. (Ref 1) performed the studies on steel coming from an experimental heat, that is a steel of chemical composition corresponding to the matrix of the steel containing $2.3 \% \mathrm{C}$ and $12 \% \mathrm{Cr}$ hardened after austenitizing at $950{ }^{\circ} \mathrm{C}$ for a period of $60 \mathrm{~min}$. Thus, the steel contained $0.59 \% \mathrm{C}$ and $4.73 \% \mathrm{Cr}$. According to Sato et al. in this steel, the transformation of carbides during tempering occurs after the scheme:

$$
\mathrm{M}^{\prime} \rightarrow \varepsilon \rightarrow \Theta \mathrm{M}_{3} \mathrm{C} \rightarrow \mathrm{M}_{7} \mathrm{C}_{3} .
$$

Almost at the same time Apajew (Ref 2) announced that chromium steels with the ratio $\mathrm{Cr} / \mathrm{C}>3$, the carbides transformations occur according to the scheme:

$$
\mathrm{M} \rightarrow \varepsilon \rightarrow \mathrm{Fe}_{3} \mathrm{C} \rightarrow(\mathrm{Fe}, \mathrm{Cr})_{3} \mathrm{C} \rightarrow(\mathrm{Cr}, \mathrm{Fe})_{7} \mathrm{C}_{3},
$$

whereas according to Kimura (Ref 3 ) during the study of that type of steel there are only the carbides $\mathrm{M}_{7} \mathrm{C}_{3}$, with the amount rising with increasing tempering temperature.

In Poland, studies of carbide precipitation during steel tempering were performed by Głowacki (Ref 4, 5), and

Tadeusz Nykiel and Tadeusz Hryniewicz, Faculty of Mechanical Engineering, Koszalin University of Technology, Racławicka 15-17, 75-620 Koszalin, Poland. Contact e-mail: Tadeusz.Hryniewicz@, tu.koszalin.pl.
Kowalski (Ref 6), and the steel with the additions of tungsten and vanadium by Kaluża (Ref 7), and Nykiel (Ref 8), Nykiel and Hryniewicz (Ref 9-14). According to Głowacki (Ref 4), in the steels $195 \mathrm{H} 12 / \mathrm{NC11}$, and with substantial content of nitrogen $(\mathrm{NC} 11 \mathrm{~N}$ steel with $0.06 \mathrm{~N})$ during tempering, the transition carbides $\varepsilon, \chi$, and $\mathrm{Fe}_{3} \mathrm{C}$ are formed, and $\mathrm{M}_{3} \mathrm{C}$ and $\mathrm{M}_{7} \mathrm{C}_{3}$ form at higher temperatures. According to Kowalski (Ref 6 ) in the steel of type $165 \mathrm{H} 12 / \mathrm{NC} 10$ hardened after austenitizing at $1000{ }^{\circ} \mathrm{C}$ through a period of 15 min during tempering the carbides $\mathrm{Fe}_{\mathrm{x}} \mathrm{C}$ precipitate, which transform into $\mathrm{M}_{3} \mathrm{C}$ and these, during tempering at $450-700{ }^{\circ} \mathrm{C}$, are transformed into chromium-iron carbides $\mathrm{M}_{7} \mathrm{C}_{3}$. In other studies (Ref 7, 9-11), concerned with carbides precipitation during tempering the steel of type $217 \mathrm{H} 12 \mathrm{WF}$, it was not unilaterally established that $\chi$ carbides arise. In the literature, there is lack of complete elaboration concerned with the carbide precipitation process during tempering of this type of steels.

Different aspects concerning behavior of $\mathrm{M}_{7} \mathrm{C}_{3}$ carbides in steels were considered recently (Ref 11-22). Stacking faults within iron-chromium carbide of the type $(\mathrm{Fe}, \mathrm{Cr})_{7} \mathrm{C}_{3}$ were observed by Carpenter et al. (Ref 17-19). Intragranular precipitation of the carbide $\mathrm{M}_{7} \mathrm{C}_{3}$ (M: randomly dispersed $\mathrm{Fe}, \mathrm{Cr}, \mathrm{Ni}$ ) under prolonged low-temperature gas-phase carburization of AISI 316L-type austenitic stainless steel was observed by Ernst et al. (Ref 20). The effect of chromium content on the oxidation behavior of high-speed steels under dry and moist air environments was studied by Monteiro and Rizzo (Ref 21). Compositional changes in carbide $\mathrm{M}_{7} \mathrm{C}_{3}$ upon annealing and the effect of $\mathrm{Cr}$ content on microstructure and properties of medium-alloy high-carbon tool and die steels were studied by Palcut et al. (Ref 22), and Zhang et al. (Ref 23), respectively. Kinetics of phase transformations during tempering of tool steels with different carbon contents was studied by Bała (Ref 24).

In the literature, there is lack of in-depth research works concerning the processes of carbide precipitation during tempering of this type of steel. The basic aim of this work 
was to establish what carbides are formed during 2-h tempering of D3 (or 217H12WF) steel hardened after austenitizing at $1050{ }^{\circ} \mathrm{C}$ throughout $30 \mathrm{~min}$ time. The identifying carbide identification studies were performed by the method of electron diffraction from extraction carbides replicas.

Table 1 Chemical composition of the D3 tool steel studied, wt.\%

\begin{tabular}{lll}
\hline C 1.95 & Mo 0.05 & Mn 0.44 \\
Cr 11.56 & Ni 0.122 & P 0.024 \\
W 1.32 & Cu 0.073 & S 0.022 \\
V 0.31 & Si 0.027 & N 0.016 \\
\hline
\end{tabular}

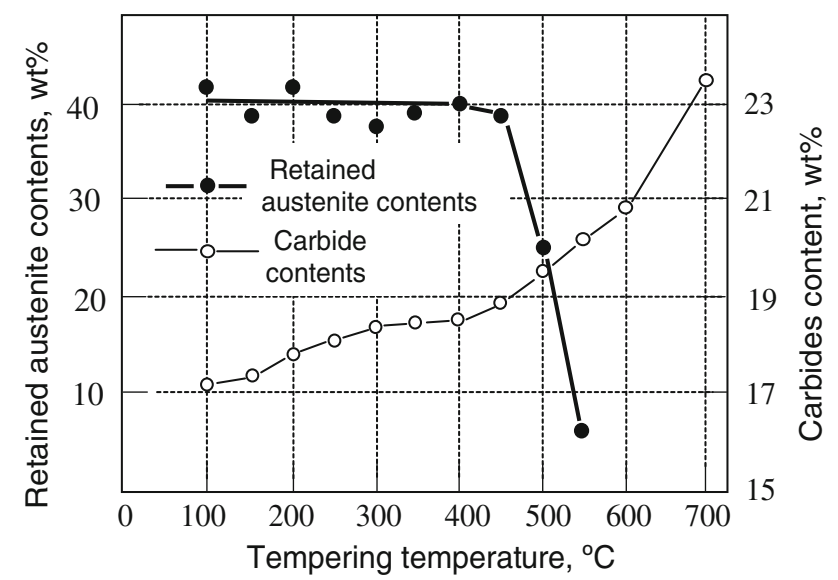

Fig. 1 Effect of tempering temperature on the retained austenite and carbides contents of the studied steel of type AISI D3 (217H12WF) tool steel
The results of this study will be helpful in solving the problems concerning adhesion and life of superhard layers coating over the working surface of tools made of this type of steel. It is worth stating that the other authors' ways are just as valid but different in getting a response for technological problems.

\section{Material and Method}

\subsection{Chemical Composition of the Steel and Heat Treatment}

The studies were performed on D3 tool steel of composition given in Table 1. The samples for the studies were made of rods with diameter $13 \mathrm{~mm}$, forged soft annealed, and coming from the same heat.

\subsection{Study Method}

Method of heat treatment, microscopic studies on an optical microscope, the studies of hardness and determination of retained austenite contents by a magnetic method, and carbides by electrolytic extraction method were given in previous publications (Ref 9-14).

2.2.1 Metallographic Studies by Means of an Electron Microscope by Extraction Replicas Method. Carbide replicas were made. Microsections of samples ( $\phi 12 \mathrm{~mm}$ ) were prepared mechanically using abrasive papers and diamond pastes. After a selective etching of a microsection, the surface matrix was prepared by means of Triafol-TN. Then the TriafolTN matrix was coated by carbon, and the Triafol-TN layer was dissolved. The structure photographs and electron diffractions from extraction replicas were performed at an acceleration voltage of $100 \mathrm{kV}$. The carbide phase analysis was performed based on $d_{\mathrm{hkl}}$ value given in previous publications (Ref 25, 26).

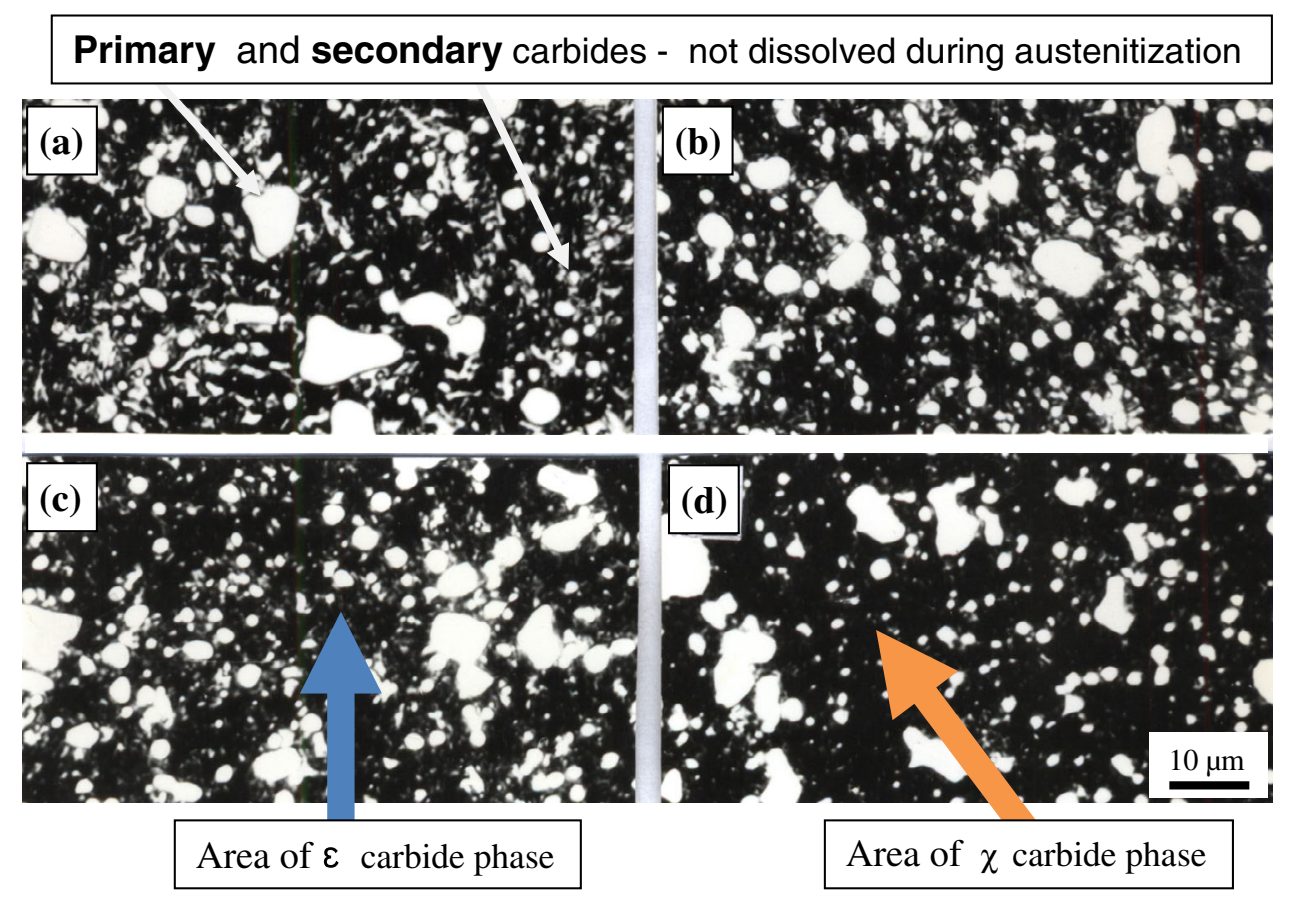

Fig. 2 Effect of annealing temperature on the structure of studied AISI D3 tool steel hardened after austenitizing at $1050{ }^{\circ} \mathrm{C}$ for 30 min: (a) hardened after tempering, (b) $350{ }^{\circ} \mathrm{C}$, (c) $500{ }^{\circ} \mathrm{C}$, (d) $700{ }^{\circ} \mathrm{C}$. Tempering time $120 \mathrm{~min}$, magn. $\times 900$ 


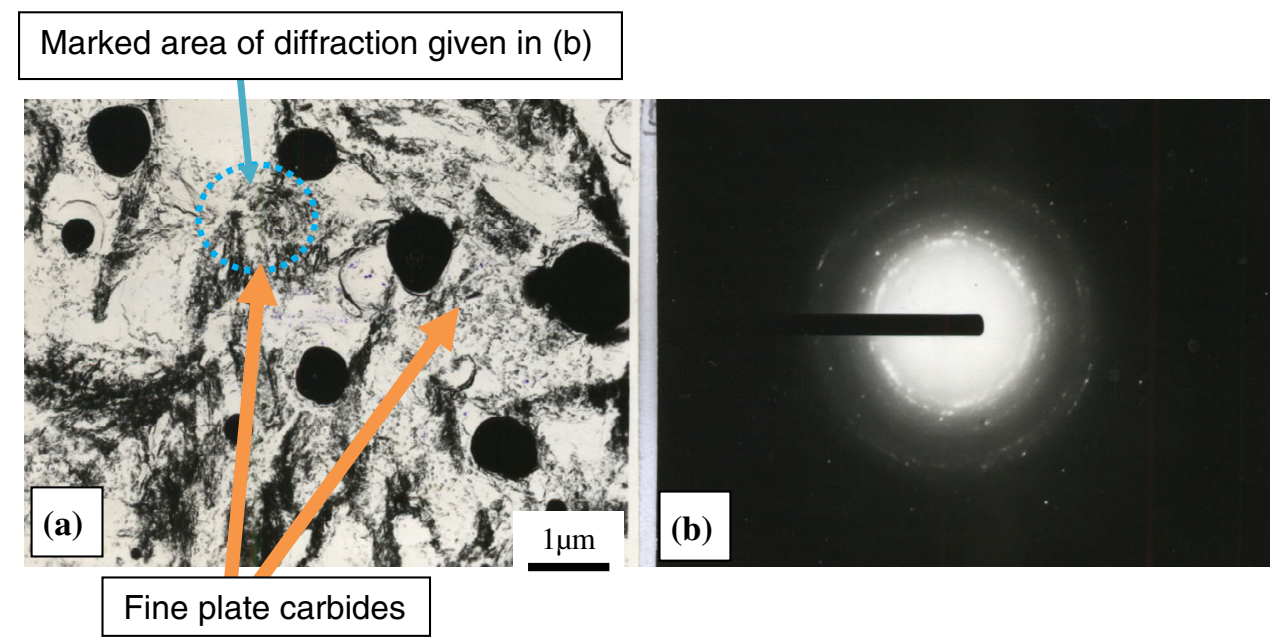

Fig. 3 Electron microscopy images of AISI D3 tool steel hardened after austenitizing at $1050{ }^{\circ} \mathrm{C}$ for 30 min and tempered at $200{ }^{\circ} \mathrm{C}$ : (a) extraction replica, magn. $\times 9000$, (b) diffraction pattern of the area with fine plate carbides
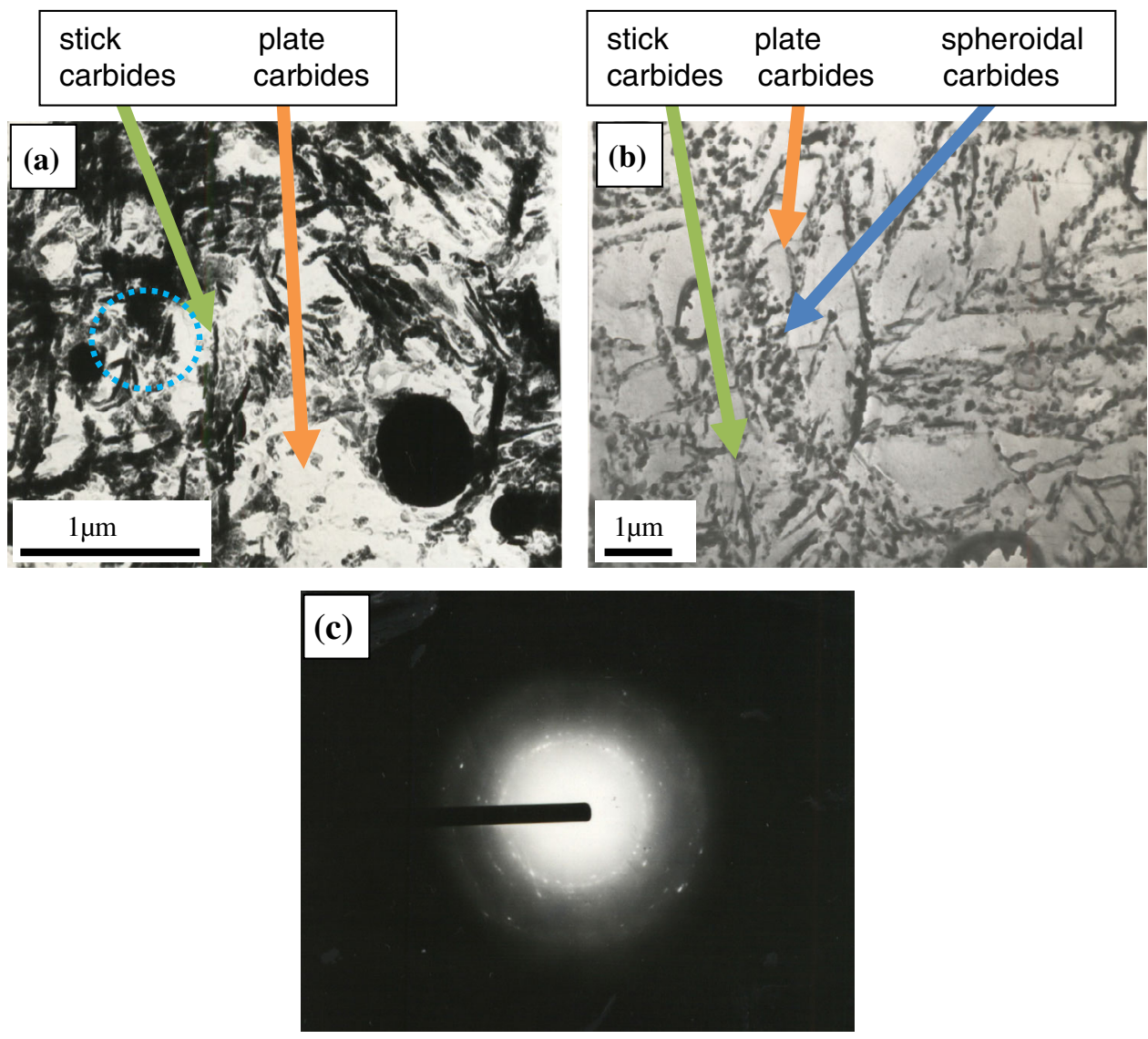

Fig. 4 Electron microscopy images of AISI D3 tool steel hardened after austenitizing at $1050{ }^{\circ} \mathrm{C}$ for 30 min and tempered at $350{ }^{\circ} \mathrm{C}$. Extraction replica: (a) area 1, magn. $\times 22000$, (b) area 2, magn. $\times 8000$, (c) diffraction pattern of the area with rod- and plate-like carbides

\section{Results}

In this work, the study results of tempering performed on AISI D3 (217H12WF) tool steel under consecutive increasing temperatures are given. Changes in retained austenite and carbide contents are presented in Fig. 1. A sharp drop in the retained austenite contents is observed above $450{ }^{\circ} \mathrm{C}$, whereas the carbide contents grow steadily with a steeper growth in the tempering temperature range of $600-700{ }^{\circ} \mathrm{C}$.

The resulting changes in structure and identification of carbides by means of a transmission electron microscope and extraction replicas were investigated. The studies were performed on samples after tempering at the following temperatures: $200,350,500,600$, and $700{ }^{\circ} \mathrm{C}$. Selected from the 

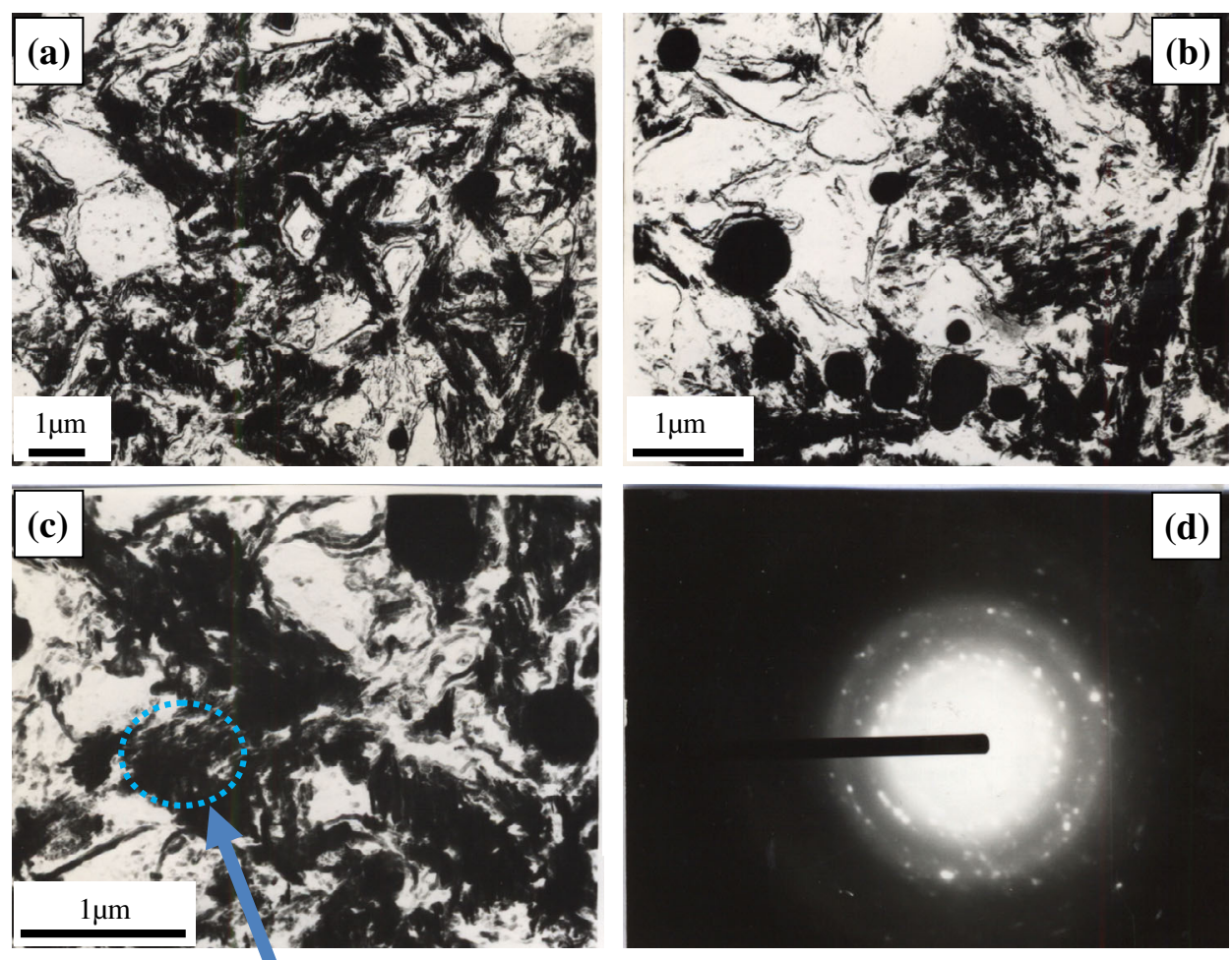

Area of distinct coagulation of carbides, with a diffraction pattern given in (d)

Fig. 5 Electron microscopy images of AISI D3 tool steel hardened after austenitizing at $1050{ }^{\circ} \mathrm{C}$ for 30 min and tempered at $500{ }^{\circ} \mathrm{C}$. Extraction replica. The areas (a, b, c) with magnification $\times 7000, \times 12000$, and $\times 16000$, respectively; (d) diffraction pattern of the area with clearly visible carbides coagulation
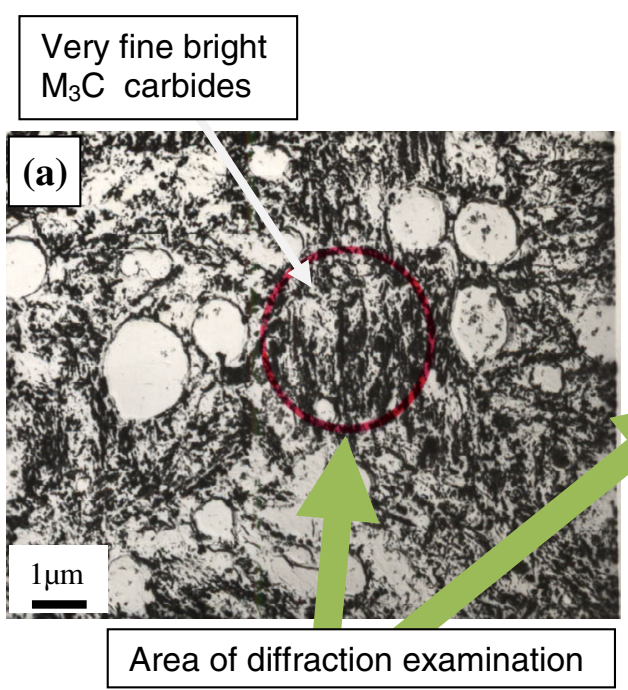
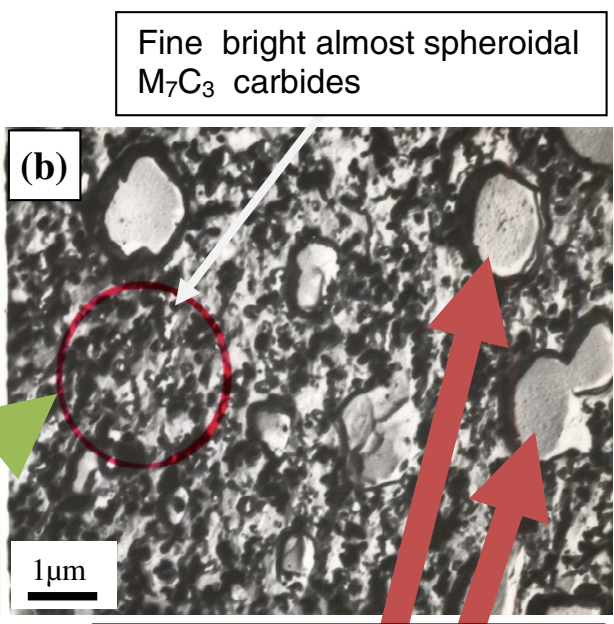

Primary carbides, not dissolved

Fig. 6 Electron microscopy images of AISI D3 tool steel hardened after austenitizing at $1050{ }^{\circ} \mathrm{C}$ for 30 min and tempered at: (a) $600{ }^{\circ} \mathrm{C}$, (b) $700{ }^{\circ} \mathrm{C}$. Extraction replicas under magnification $\times 6300$, and $\times 8000$, respectively. The areas of diffraction pattern examination are marked by circles

studies (Fig. 2), the steel microstructures and diffraction patterns of extraction replicas have been presented in the following Fig. 3-6.

During tempering at $200{ }^{\circ} \mathrm{C}$, very fine carbides of plate shape (Fig. 3) arise in the region of martensite. The diffraction studies of replicas revealed that they are transition iron carbides $\varepsilon$ and $\chi$; also, $\mathrm{Fe}_{3} \mathrm{C}$ carbides occur.
During tempering at $350{ }^{\circ} \mathrm{C}$, carbides that earlier precipitated from martensite assume the shape of a stick/rod. Then, the carbides of plate shape and the orientation in agreement with martensite orientation precipitate (Fig. 4), with some precipitated carbides, assuming spheroidal shape. The occurrence of carbides of a spheroidal shape, besides the rod/stick-like ones, is visible in Fig. 3. The diffraction replicas studies have 
revealed that in the areas of martensite occurrence, the $\varepsilon, \chi$, and $\mathrm{Fe}_{3} \mathrm{C}$ carbides are formed.

After tempering at $500{ }^{\circ} \mathrm{C}$, the phenomenon of forming a large number of plate-like carbides draws the attention in some matrix locations (Fig. 5). Occurrence of these carbides may result from the pearlitic transformation of the retained austenite. Some of them, due to coagulation occurrence, assume a sticklike form successively.

The phase analysis, using the method of electron diffraction of replicas, revealed that during tempering at $600{ }^{\circ} \mathrm{C}$, the $\chi, \mathrm{M}_{3} \mathrm{C}$, and $\mathrm{M}_{7} \mathrm{C}_{3}$ carbides arise in the steel, whereas after tempering at $700{ }^{\circ} \mathrm{C}$, besides $\mathrm{M}_{7} \mathrm{C}_{3}$ carbides, some traces of $\mathrm{M}_{3} \mathrm{C}$ carbides have appeared. Tempering at $700{ }^{\circ} \mathrm{C}$ results in an intensive coagulation, coalescence, and spheroidisation of carbides precipitated from the matrix. The shape of these carbides, however, clearly departs from the spheroidal one (Fig. 6).

\section{Conclusions}

Based on the experimental studies carried out, the following conclusions may be formulated:

(1) In the studied steel of type D3 (or 217H12WF), hardened after austenitizing at $1050{ }^{\circ} \mathrm{C}$ for $30 \mathrm{~min}$ and tempering during $2 \mathrm{~h}$ at the temperature range of 200$700{ }^{\circ} \mathrm{C}$, the following carbides are formed:

$200{ }^{\circ} \mathrm{C} \rightarrow \varepsilon+\chi+\mathrm{Fe}_{3} \mathrm{C}, 350{ }^{\circ} \mathrm{C} \rightarrow \varepsilon+\chi+\mathrm{Fe}_{3} \mathrm{C}$,

$500{ }^{\circ} \mathrm{C} \rightarrow \chi+\mathrm{M}_{3} \mathrm{C}+\mathrm{M}_{7} \mathrm{C}_{3}, 600{ }^{\circ} \mathrm{C} \rightarrow \chi+\mathrm{M}_{3} \mathrm{C}+\mathrm{M}_{7} \mathrm{C}_{3}$,

$$
700{ }^{\circ} \mathrm{C} \rightarrow \mathrm{M}_{3} \mathrm{C}+\mathrm{M}_{7} \mathrm{C}_{3},
$$

Apart from higher mentioned carbides, there are also big primary carbides and fine secondary $\mathrm{M}_{7} \mathrm{C}_{3}$ carbides which have not dissolved during austenitizing. The weight fraction of these carbides equals about $17.2 \%$.

(2) Based on the studies performed, as well as the literature data, one may assume the following sequence of carbides precipitation

$$
\mathrm{M} \rightarrow \varepsilon \rightarrow \chi \rightarrow \mathrm{Fe}_{3} \mathrm{C} \rightarrow \mathrm{M}_{3} \mathrm{C} \rightarrow \mathrm{M}_{3} \mathrm{C}+\mathrm{M}_{7} \mathrm{C}_{3}
$$

in the studied steel, with $\varepsilon$ carbide occurring in the tempering temperature range up to about $350{ }^{\circ} \mathrm{C}$, and $\chi$ carbides up to $600{ }^{\circ} \mathrm{C}$.

\section{Open Access}

This article is distributed under the terms of the Creative Commons Attribution License which permits any use, distribution, and reproduction in any medium, provided the original author(s) and the source are credited.

\section{References}

1. T. Sato, Y. Honda, and T. Nishizawa, Study on Carbides in Practical Special Steels by Electrolytic Isolation (II) (On Carbides in High C-High Cr Die Steel), Tetsu To Hagane, 1956, 44(12), p 1118-1122

2. B.A. Apajew, Phase transformations during tempering of highchromium tool steel, Fiz. Met. Metalloved., 1958, 6(5), p 858-865 (in Russian)

3. S. Kimura, On the Carbides Studies in Tool Steels, Hitachi Hyoron, $1963, \mathbf{4 5}(2)$, p 355-359
4. Z. Głowacki, The Studies Over Carbides in Chromium Steels (in Polish). 5th PAN Seminar of Metallurgy Committee, Zakopane 25-27, 1968, p 1-17

5. Z. Głowacki, K. Kałuża, and J. Baranowski, Carbides, Nitrides, Borides, 2nd International Conference Poznań-Kołobrzeg, 30 Sept-4 Oct, 1981, p 228-238

6. W. Kowalski, Heat Treatment and Carbides Transformation in Tool Steels, Prace Instytutu Mechaniki Precyzyjnej, 1966, 14(4), p 1-18 (in Polish)

7. K. Kałuża, Effect of Heat Treatment on Carbides Transformation in NCWV Tool Steel, PhD Thesis, Politechnika Poznańska, Poznań, 1979 (in Polish)

8. T. Nykiel, Effect of Austenitizing Conditions on Carbides Transition to $\gamma$ Solution in NCWV Tool Steel (in Polish), PhD Thesis, Politechnika Poznańska, Poznań, 1982

9. T. Nykiel and T. Hryniewicz, Kinetics of Carbides Dissolution During Austenitizing of Tool Steel D3 (2\% C and 12\% Cr with Additives of W, Mo, V), Proceedings of the 6th International Seminar IFHT, Kyongju TEMF Hotel, 15-18 Oct, Korea, 1997, p 238-245

10. T. Nykiel and T. Hryniewicz, Effect of Austenitizing Parameters on the Change of Concentration of Alloying Components and Phase Structure of Tool Steel of Type $2 \% \mathrm{C}$ and $12 \% \mathrm{Cr}$ with Additives of W, Mo, V, Proceedings of the 11th Congress of the International Federation for Heat Treatment and Surface Engineering, Florence, Italy, 19-21 October, 1998, 116, p 87-96

11. T. Nykiel and T. Hryniewicz, On the $\mathrm{M}_{7} \mathrm{C}_{3}$ Carbides Coagulation and Coalescence During High-Temperature Austenitizing of $2 \% \mathrm{C}$ and $12 \%$ Cr Type Steel, Adv. Mater. Sci., 2003, 4(2), p 61-70

12. T. Nykiel and T. Hryniewicz, Effect of Tempering on the Structure and Coercive Force in AISI D3 (217H12WF) Ledeburite Chromium Steel, Proceedings of 17th International Metallurgy and Materials Conference METAL2008, Steel Product-Properties, Hradec nad Moravici, Czech Republic, 13-15 May, 2008, C24

13. T. Nykiel and T. Hryniewicz, The Effect of Tempering Temperature on Carbides and Matrix of Steel of Type 217H12WF. Part 1. Separation of carbides, Proceedings of 18th International Conference on Metallurgy and Materials Conference METAL2009, Steel Product-Properties, Hradec nad Moravici, Czech Republic, 19-21 May, 2009, C10

14. T. Nykiel and T. Hryniewicz, Erratum to: Effect of Tempering on the Structure and Coercive Force in the AISI, D3 (217H12WF) Ledeburite Chromium Steel, Trans. Indian. Inst. Met., 2012, 65(2), p 219-230

15. T. Hryniewicz and T. Nykiel, Effect of Austenitizing Parameters and SubZero Treatment on Kinetics of Retained Austenite Transformation in NCWV/D3 Tool Steel, Inżynieria Materiałowa, 2000, 114(1), p 32-36

16. T. Hryniewicz and T. Nykiel, Activation Energy of Carbides Dissolving in Austenite of the Tool Steel D3, Proceedings of the 6th International Seminar IFHT, Kyongju TEMF Hotel, 15-18 October, Korea, 1997, p 253-260

17. S.D. Carpenter and D. Carpenter, X-Ray Diffraction Study of $\mathrm{M}_{7} \mathrm{C}_{3}$ Carbide Within a High Chromium White Iron, Mater. Lett., 2003, 57, p 4456-4459

18. S.D. Carpenter and D. Carpenter, Stacking Faults and Superlattice Observations During Transmission Electron Microscopy of a (Fe, Cr)7C3 Carbide, Mater. Lett., 2003, 57, p 4460-4465

19. S.D. Carpenter, D.E.O.S. Carpenter, and J.T.H. Pearce, The Nature of Stacking Faults Within Iron-Chromium Carbide of the Type (Fe, Cr)7C3, J. Alloys Compd., 2010, 494, p 245-251

20. F. Ernst, D. Li, H. Kahn, G.M. Michal, and A.H. Heuer, The Carbide $\mathrm{M}_{7} \mathrm{C}_{3}$ in Low-Temperature-Carburized Austenitic Stainless Steel, Acta Mater., 2011, 59, p 2268-2276

21. M.J. Monteiro and F.C. Rizzo, Effect of Chromium Content on the Oxidation Behaviour of High-Speed Steels Under Dry and Moist Air Environments, Mater. Sci. Forum, 2005, 522-523, p 171-180

22. M. Palcut, V. Vach, R. Cicka, and J. Janovec, Compositional Changes in Carbide $\mathrm{M}_{7} \mathrm{C}_{3}$ Upon Annealing, Arch. Metall. Mater, 2008, 53(4), p 1157-1164

23. Y. Zhang, G. Zong, K. Shui, and M. He, Effect of Cr Content on Microstructure and Properties of Medium-Alloy High Carbon Tool and Die Steel, Heat Treat. Met., 2010, 10, p 44-47

24. P. Bała, The Kinetics of Phase Transformations during Tempering of Tool Steels with Different Carbon Content, Arch. Metall. Mater., 2009, 54(2), p 491-498

25. K.W. Andrews, D.J. Dyson, and S.R. Keown, Interpretation of Electron Diffraction Patterns, A. Hilges Ltd., London, 1971

26. A. Barbacki, Method of Crystallographic Analysis in Electron Microscopy, Ed. Politechnika Poznańska, Poznań 1985 (in Polish) 